\title{
One-pot synthesis of magnetic algal carbon/sulfidated nanoscale zerovalent iron composites for removal of bromated disinfection by- product
}

\author{
Jian Lu ${ }^{\text {a }}$, Cui Zhang ${ }^{\mathrm{a}}$, Jun $\mathrm{Wu}^{\mathrm{b}, *}$ \\ ${ }^{a}$ CAS Key Laboratory of Coastal Environmental Processes and Ecological Remediation, Yantai Institute of Coastal Zone Research (YIC), Chinese Academy of \\ Sciences (CAS), Shandong Key Laboratory of Coastal Environmental Processes, YICCAS, Yantai, Shandong, 264003, PR China \\ b School of Resources and Environmental Engineering, Ludong University, Yantai, Shandong, 264025, PR China
}

\section{H I G H L I G H T S}

- Algal carbon/sulfidated $\mathrm{Fe}^{0}$ nanoflower composite was prepared through one-pot method.

- More than $98 \%$ of the bromate was removed within 48 min using S-nZVI/ AC composite.

- Removal rate constant of S-nZVI/AC treatment was twice that of S-nZVI control.

- Removal rate constant increased three times when $\mathrm{S} / \mathrm{Fe}$ ratio increased from 0 to 0.3

- S-nZVI/AC composite might be a promising water purification material.

\section{A R T I C L E I N F O}

\section{Article history:}

Received 30 September 2019

Received in revised form

23 January 2020

Accepted 15 February 2020

Available online 19 February 2020

Handling Editor: Peizhe Sun

\section{Keywords:}

Algal carbon

One-pot

Bromate

Sulfidated iron

Nanoscale composite
G R A P H I C A L A B S T R A C T

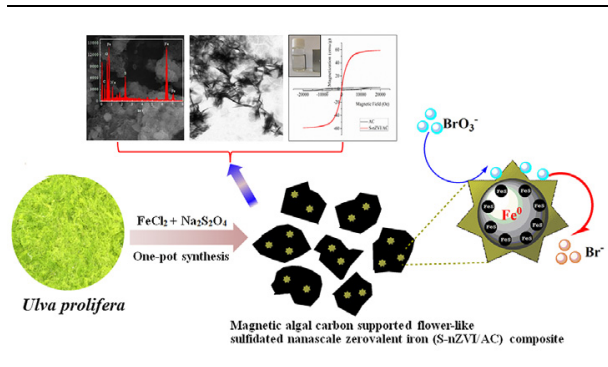

\begin{abstract}
A B S T R A C T
Magnetic algal carbon supported flower-like sulfidated nanoscale zerovalent iron (S-nZVI/AC) composite was firstly synthesized through one-pot method and used for removing bromate. More than $98 \%$ of bromate was efficiently removed within $48 \mathrm{~min}$. Compared with the individual S-nZVI treatment, the removal rate constant of the S-nZVI/AC composite treatment was almost doubled. The removal rate constant of bromate increased three times when the $\mathrm{S} / \mathrm{Fe}$ ratio increased from 0 to 0.3 . According to the synergistic effect between the algal carbon and S-nZVI on the bromate removal, the introduction of carbon and sulfide-modification of nZVI were efficient modification approaches for enhancing the removal of bromated using S-nZVI/AC composite. The removal efficiency of bromate increased sharply to more than $98 \%$ when the composite dose increased from 0 to $40 \mathrm{mg} \mathrm{L}^{-1}$. The removal rate constant increased linearly from 0.08 to $0.31 \mathrm{~min}^{-1}$ when the initial concentration increased from 50 to $200 \mu \mathrm{g} \mathrm{L}{ }^{-1}$. The removal efficiency of the bromate still maintained at high level (>85\%) after 5 recycles of the S-nZVI/AC composite. Bromate was readily removed under neutral or slight acidic conditions. The bromate removal rate constant increased from 0.10 to $0.27 \mathrm{~min}^{-1}$ when the temperature increased from 15 to $35{ }^{\circ} \mathrm{C}$. The bromate removal rate constant increased almost 4 times when the ionic strength increased from 0 to $3 \mathrm{~g} \mathrm{~L}^{-1}$. This study demonstrates that S-nZVI/AC composite synthesized through one-
\end{abstract}

\footnotetext{
* Corresponding author.

E-mail address: wujunlisa@163.com (J.Wu).
} 
pot method is a promising water purification material for efficient removal of bromated disinfection byproduct.

() 2020 Elsevier Ltd. All rights reserved.

\section{Introduction}

Bromate $\left(\mathrm{BrO}_{3}^{-}\right)$, a common bromated disinfection by-product, is usually formed in bromide-containing water during the ozonation or chlorination process (Zhang et al., 2016). Bromate is considered to be potentially carcinogenic and nephrotoxic so as to be classified as a category I, group B2 carcinogen (Kurokawa et al., 1990; Sun et al., 2015). The acceptable maximum level of bromate in drinking water recommended by the US Environmental Protection Agency and China National Standards is $10 \mu \mathrm{g} \mathrm{L}^{-1}$. Bromate is very stable in water to make its removal difficult (Butler et al., 2005). Many materials including Pd-containing or Ru-containing nitrogen-doped carbon nanofibers coated cordierite monoliths (Marco et al., 2013), Pd nanoparticles anchored on polyaniline supported by mesoporous SBA-15 (Sun et al., 2015), acid-washing aluminum scrap (Lin et al., 2017), and zerovalent iron (Zhang et al., 2016) have been used for removing bromate contaminants from water systems.

Nanoscale zero-valent iron (nZVI) is a reducing agent with a significantly large surface area and colloidal effect (Zhang, 2003; Qian et al., 2017). Due to its high activity, nZVI has received increasing attention for the removal of various pollutants through chemical reduction processes (Zhang, 2003; Song et al., 2017; Wang et al., 2017). However, zero-valent iron is not thermodynamically stable in water and is subjected to corrosion by water itself, producing gases such as hydrogen or dinitrogen (Gong et al., 2016). Besides zero-valent iron, iron sulfide is also an efficient, economic, and environmentally friendly reducing agent which can provide a source of $\mathrm{Fe}(\mathrm{II})$ and sulfide for the reductive removal of many pollutants (Lyu et al., 2017). The FeS coated sand, limestone, and biochar have been used for removing $\mathrm{As}(\mathrm{III})$ and $\mathrm{Cr}(\mathrm{VI})$ (Han et al., 2011; Gong et al., 2012; Lyu et al., 2017). This suggests that FeS might serve as a protection layer on the surface for preventing corrosion of n-ZVI by water and removing pollutants (Gong et al., 2012, 2017). Sulfide-modified nanoscale zerovalent iron (S-nZVI) has shown faster and more efficient removal of trichloroethylene (TCE), diclofenac, $\mathrm{Cr}(\mathrm{VI})$, and tetrabromobisphenol from water than pure $\mathrm{Fe}^{0}$ nanoparticles (Kim et al., 2011; Li et al., 2016; Song et al., 2017; Zou et al., 2019). Su et al. (2015) reported that FeS/Fe nanoparticles at an $\mathrm{S} / \mathrm{Fe}$ molar ratio of 0.28 had the maximum sorption capacity of $85 \mathrm{mg} \mathrm{g}^{-1}$ for $\mathrm{Cd}^{2+}$, which was more than $100 \%$ higher than that of nZVI. Simultaneous removal of $\mathrm{Cr}(\mathrm{IV})$ and $\mathrm{Sb}(\mathrm{III})$ with high performance using sulfidated zerovalent iron was also reported (Wang et al., 2018).

Both nanoscale $\mathrm{Fe}$ and FeS particles are unstable and can agglomerate rapidly in aqueous solutions (Gong et al., 2012; Zhang et al., 2016). Therefore, it is essential to prevent the aggregation of these nanoscale particles so as to enhance their reactivity and retain efficient removal of pollutants (Gong et al., 2012; Wang et al., 2017). Studies have reported that the porous carbon material with large surface area can serve as the effective supporter of nZVI to prevent nZVI aggregation, and thus enhance the removal of arsenate, trichloroethylene, dye, and antibiotics (Gong et al., 2012; Quan et al., 2014; Yan et al., 2015; Wei et al., 2019). Additionally, nZVI has been considered as a promising material for the modification of carbon material due to its excellent magnetic property, which could improve the separation of solid spent sorbent material from aqueous solution (Wang et al., 2017). Although the beneficial effect of the carbon structure of carbon materials on the dispersal of nanoscale particles is anticipated, few studies have described the pollution control of the carbon materials supported sulfidated nanoscale zerovalent iron (S-nZVI).

Ulva prolifera ( $U$. prolifera) which is a marine macroalgae can form green tides due to the marine eutrophication has become a huge burden for both environment and economic development in the coastal zone (Lu et al., 2017; Zhang et al., 2019). Excessive $U$. prolifera biomass continues to thrive in the coastal and offshore zone year after year (Lu et al., 2017). Therefore, it is of great practical significance to make full use of harmful algal biomass. Due to the abundance of basic nitrogen-containing groups on the surface of the algal carbon, the algae-based carbon indicated good performance in the removal of anionic contaminants (Lu et al., 2017). Various porous carbon materials are gaining interests due to its high surface area, and chemical resistance to acidic conditions (Yao et al., 2012; Shcherban et al., 2014; Wu et al., 2016; Sun et al., 2018). Although porous carbon has been widely used for the removal of various contaminants, it usually offers low removal efficiency of bromate (Hong et al., 2016). In this study, algal carbon supported flower-like S-nZVI composite was firstly synthesized through onepot method and its performance for the removal of bromate was investigated. The impacts of various factors such as $\mathrm{S} / \mathrm{Fe}$ ratio, initial concentration, $\mathrm{pH}$, temperature, and ionic strength were also evaluated. The main objective of this study was to obtain initial information on the bromate removal using algal carbon supported sulfidated nanoscale zerovalent iron (S-nZVI/AC) composite.

\section{Materials and methods}

\subsection{Chemicals and reagents}

Standards of bromate ( $\geq 99 \%$ ) were purchased from Macklin Inc. (Shanghai, China). Deionized (DI) water was purified using a MilliQ Plus system (Millipore, USA). All other reagents used in this study were of reagent grade. The synthetic wastewater containing bromate was made by adding bromate into DI water.

\subsection{Preparation of the S-nZVI/AC composite}

U. prolifera were collected on the beach of Rushan city, China. The pre-cleaned fresh algae were crushed and ground in a household mixer grinder for $2 \mathrm{~min}$. For the preparation of S-nZVI/BC, $3.98 \mathrm{~g}$ of $\mathrm{FeCl}_{2} \bullet 4 \mathrm{H}_{2} \mathrm{O}$ and $0.52 \mathrm{~g}$ of $\mathrm{Na}_{2} \mathrm{~S}_{2} \mathrm{O}_{4}$ powders were mixed with algal slurry ( $20 \mathrm{~g}$ ) using the same mixer grinder. Further, the mixed slurry was transferred into a high-pressure polyethylene reaction pot and placed in a tubular furnace at $180^{\circ} \mathrm{C}$ for $4 \mathrm{~h}$. The obtained materials were washed several times with deoxyethanol followed by drying in the freeze-dryer (FD-1A-50, Boyikang, Beijing, China), then screened with a 60 -mesh sieve for subsequent adsorption experiment. The resulting molar ratio of $\mathrm{S} / \mathrm{Fe}$ was 0.3 . For comparison, the algal slurry (15 g) without addition of $\mathrm{FeCl}_{2} \bullet 4 \mathrm{H}_{2} \mathrm{O}$ and $\mathrm{Na}_{2} \mathrm{~S}_{2} \mathrm{O}_{4}$ were also conducted by the same procedure and labeled as AC. In order to know the effects of the $\mathrm{S} / \mathrm{Fe}$ ratio $(0,0.1,0.2,0.3$, and 0.4$)$ on the removal of bromate, The $\mathrm{Na}_{2} \mathrm{~S}_{2} \mathrm{O}_{4}(0,0.17,0.35,0.52$, and $0.70 \mathrm{~g})$ was then added into the 
algae slurry (20 g) for the synthesis of S-nZVI/AC composite with different $\mathrm{S} / \mathrm{Fe}$ ratio.

To obtain information of the synergistic effect between the algal carbon and S-nZVI on the bromate removal using S-nZVI/AC composite, nano-materials without AC including S-nZVI, nZVI, and $\mathrm{nFeS}$, and the combined composites including nZVI + AC composite, $\mathrm{FeS}+\mathrm{AC}$ composite, and AC were prepared. To prepare the SnZVI, $150 \mathrm{~mL}$ of the $\mathrm{NaBH}_{4}\left(0.3 \mathrm{moL} \mathrm{L}^{-1}\right)$ solution with $100 \mathrm{~mL}$ of $\mathrm{Na}_{2} \mathrm{~S}_{2} \mathrm{O}_{4}\left(0.03 \mathrm{moL} \mathrm{L}^{-1}\right)$ was added dropwisely into the $100 \mathrm{~mL}$ $\mathrm{FeCl}_{2}$ solution $\left(0.20 \mathrm{moL} \mathrm{L}^{-1}\right)$ and followed by $90 \mathrm{~min}$ of vigorous stirring and continuous $\mathrm{N}_{2}$ purging. The residue particles were washed several times with deoxygenated ethanol, vacuum freezedried, and stored in a sealed vial under $\mathrm{N}_{2}$ protection prior to use. A magnet was used for the separation of the solid composites and liquids. The nZVI was prepared by replacing the $\mathrm{Na}_{2} \mathrm{~S}_{2} \mathrm{O}_{4}$ solution using de-oxygenated DI water. The nFeS was prepared by replacing the $150 \mathrm{~mL}$ of the $\mathrm{NaBH}_{4}\left(0.3 \mathrm{moL} \mathrm{L}^{-1}\right)$ solution with $100 \mathrm{~mL}$ of $\mathrm{Na}_{2} \mathrm{~S}_{2} \mathrm{O}_{4}\left(0.03 \mathrm{moL} \mathrm{L}^{-1}\right)$ using $100 \mathrm{~mL}$ of $\mathrm{Na}_{2} \mathrm{~S}\left(0.02 \mathrm{moL} \mathrm{L}^{-1}\right)$. To prepare the S-nZVI + AC composite, nZVI + AC composite, and $\mathrm{nFeS}+\mathrm{AC}$ composite, the prepared S-nZVI, nZVI, and nFeS were mixed with AC at addition dose of $30 \%$, respectively.

\subsection{Bromate removal experiments}

To estimate the applicability of S-nZVI/AC composite for the removal of bromate, $4 \mathrm{mg}$ of $\mathrm{S}-\mathrm{nZVI} / \mathrm{AC}$ was placed in a sealed flask and $100 \mathrm{~mL}$ of synthetic wastewater containing bromate was added. The S-nZVI/AC composite was added with the dose of $40 \mathrm{mg} \mathrm{L}^{-1}$. The initial concentration of bromate was $100 \mu \mathrm{g} \mathrm{L}^{-1}$. The flasks were shaken at a rolling speed of $170 \mathrm{rpm}$ under a constant temperature of $25 \pm 2{ }^{\circ} \mathrm{C}$. At the end of the experiment, the S-nZVI/ AC composite was separated from solution by a magnet. The supernatant was subjected to centrifugation $(12,000 \mathrm{rpm})$ for $5 \mathrm{~min}$ before the analysis. To perform the control experiments, the S$\mathrm{nZVI} / \mathrm{AC}$ composite was replaced by algal carbon. The $\mathrm{pH}$ of the synthetic wastewater was not adjusted except for the experiment examining the effect of $\mathrm{pH}$ on adsorptive removal. All the experiments were performed in triplicate.

To evaluate the influence of the S/Fe ratio on the removal of bromate, the S-nZVI/AC composite made under different $\mathrm{S} / \mathrm{Fe}$ ratio $(0,0.1,0.2,0.3$, and 0.4$)$ was added into reaction system. To evaluate the effect of S-nZVI/AC composite dose on the removal of bromate, the composite was added with the doses of $0,10,20,40,60$, and $80 \mathrm{mg} \mathrm{L}^{-1}$. To determine the effect of initial concentration on the removal of bromate, bromate was added to the synthetic wastewater to achieve final concentrations of $50,100,200$, and $300 \mu \mathrm{g} \mathrm{L}^{-1}$. To better understand the effect of $\mathrm{pH}$ on the removal process, the $\mathrm{pH}$ of the synthetic wastewater was adjusted to $2,4,5$, 7 , and 9 . To determine the effect of temperature on the removal of bromate, experiments were performed at various temperature conditions including $15^{\circ} \mathrm{C}, 25^{\circ} \mathrm{C}$ and $35^{\circ} \mathrm{C}$. To determine the effect of ionic strength on the removal of bromate, $\mathrm{NaCl}$ was added to the synthetic wastewater to achieve final concentrations of $0,0.3$, and $3 \mathrm{~g} \mathrm{~L}^{-1}$.

To obtain information of the synergistic effect between the algal carbon and S-nZVI on the bromate removal using S-nZVI/AC composite, control experiments without AC including S-nZVI, nZVI, and $\mathrm{nFeS}$, and the composite control experiments including nZVI $+\mathrm{AC}$ composite, $\mathrm{FeS}+\mathrm{AC}$ composite, and AC were also performed.

To evaluate the bromate removal capacity of combined S$\mathrm{nZVI}+\mathrm{AC}$ composite, the S-nZVI/AC (4 mg) was replaced by S$\mathrm{nZVI}+\mathrm{AC}, \mathrm{nZVI}+\mathrm{AC}, \mathrm{nFeS}+\mathrm{AC}$, and $\mathrm{AC}$, respectively, in the combined composite control experiments while it was replaced by $1.2 \mathrm{mg}$ of S-nZVI, nZVI, and nFeS, respectively, in the control experiments without $A C$.

\subsection{Analytical methods and data calculation}

The surface morphology of the composite was observed using a Field Emission Scanning Electron Microscope (SEM). The micrograph was taken by a Hitachi S-4800 SEM (Hitachi Company, Tokyo, Japan). An accelerating voltage of $15 \mathrm{kV}$ was used during operation, with resolution $1.2 \mathrm{~nm}$. Elemental analysis of the sample surface was determined by energy dispersive spectrometer (EDS). An OXFORD INCA EDS (OXFORD Instruments, Abingdon, UK) was employed during analysis. Transmission electron microscopy (TEM) (JEM-1200EX, JEOL, Tokyo, Japan) was used for investigating the presence and the elemental mapping of flower-like nanoparticles on the surface of algal carbon. The crystal structure of the particles was investigated by X-ray power diffraction (XRD, RigakuD/ max2500VPC, Rigaku Corporation, Tokyo, Japan) employing $\mathrm{Cu} \mathrm{K \alpha}$ radiation. The accelerating voltage was $40 \mathrm{KV}$. The magnetic properties were measured by vibration sample magnetometer (Versalab, Quantum Design, San Diego, USA) under magnetic fields up to $20 \mathrm{kOe}$. Specific surface area was determined by a surface area analyzer (Autosorb-iQ, Quantachrome Instruments, Boynton Beach, USA) using nitrogen adsorption/desorption isotherm. The X-ray photoelectron spectra (XPS) were recorded on a Thermo Scientific Escalab 250Xi X-ray photoelectron spectrometer (Thermo Fisher Scientific, Waltham, USA) at a pressure of about $2 \times 10^{-9} \mathrm{~Pa}$ with Al $\mathrm{K} \alpha \mathrm{X}$-rays as the excitation source. The Brunauer-Emmett-Teller (BET) specific surface area was calculated from the nitrogen adsorption data in the relative pressure ranging from 0.02 to 0.18 using a multipoint BET method (Quantachrome ASiQwin version 3.01). Concentrations of bromate $\left(\mathrm{BrO}_{3}^{-}\right)$and bromide $\left(\mathrm{Br}^{-}\right)$in the aqueous samples were analyzed using a Dionex ICS-2000 ion chromatograph system (Thermo Fisher Scientific, Waltham, USA) equipped with AS19 column, AG19 guard column, and ASRS suppressor. The eluent was an $8 \mathrm{mmol} \mathrm{L}^{-1} \mathrm{KOH}$ buffer solution. The removal rate constant $(k)$ and half-life $\left(t_{1 / 2}\right)$ of bromate were calculated following the previously described method (Lu et al., 2008).

\section{Results and discussion}

\subsection{Characterization of the S-nZVI/AC composite}

The presence of sulfidated iron particle on the surface of algal carbon was confirmed by SEM and EDS (Fig. 1a and b). According to the surface morphology of the S-nZVI/AC composite, flower-like nanoscale particles were unevenly distributed on the surface of algal carbon and inside the pores. The EDS confirmed that the particles on the surface of the algal carbon contained Fe and $\mathrm{S}$, indicating that the sulfidated nZVI particles were successfully supported on the algal carbon. The TEM images (Fig. 2) confirmed the presence of flower-like sulfidated nanoscale zerovalent iron nanoparticles in the S-nZVI/AC composite. According to the TEMmapping, the nano-flower on the algal carbon contained $\mathrm{Fe}$ and $\mathrm{S}$, indicating the presence of the flower-like hierarchical S-nZVI particle on the algal carbon. Only spherical S-nZVI nanoparticles were successfully synthesized in previous studies (Kim et al., 2011; Li et al., 2016; Song et al., 2017; Zou et al., 2019) while flower-like S-nZVI particles were firstly formed on the surface of porous carbon in this study. The presence of $\mathrm{O}$ in the nano-flower was mainly caused by the oxidation of the zero-valent iron. The XRD pattern of the synthesized S-nZVI/AC composite was shown in Fig. S1a. The apparent peak to $2 \theta$ of $45^{\circ}$ indicated the presence of $\mathrm{Fe}^{0}$ and $\mathrm{FeS}$ in the S-nZVI/AC composite. The broad iron peak implied the S-nZVI particles had an amorphous structure. The result was similar to the findings of previously synthesized nZVI particles (Fang et al., 2011). Fig. S1b showed hysteresis loop of the algal carbon with S-nZVI 

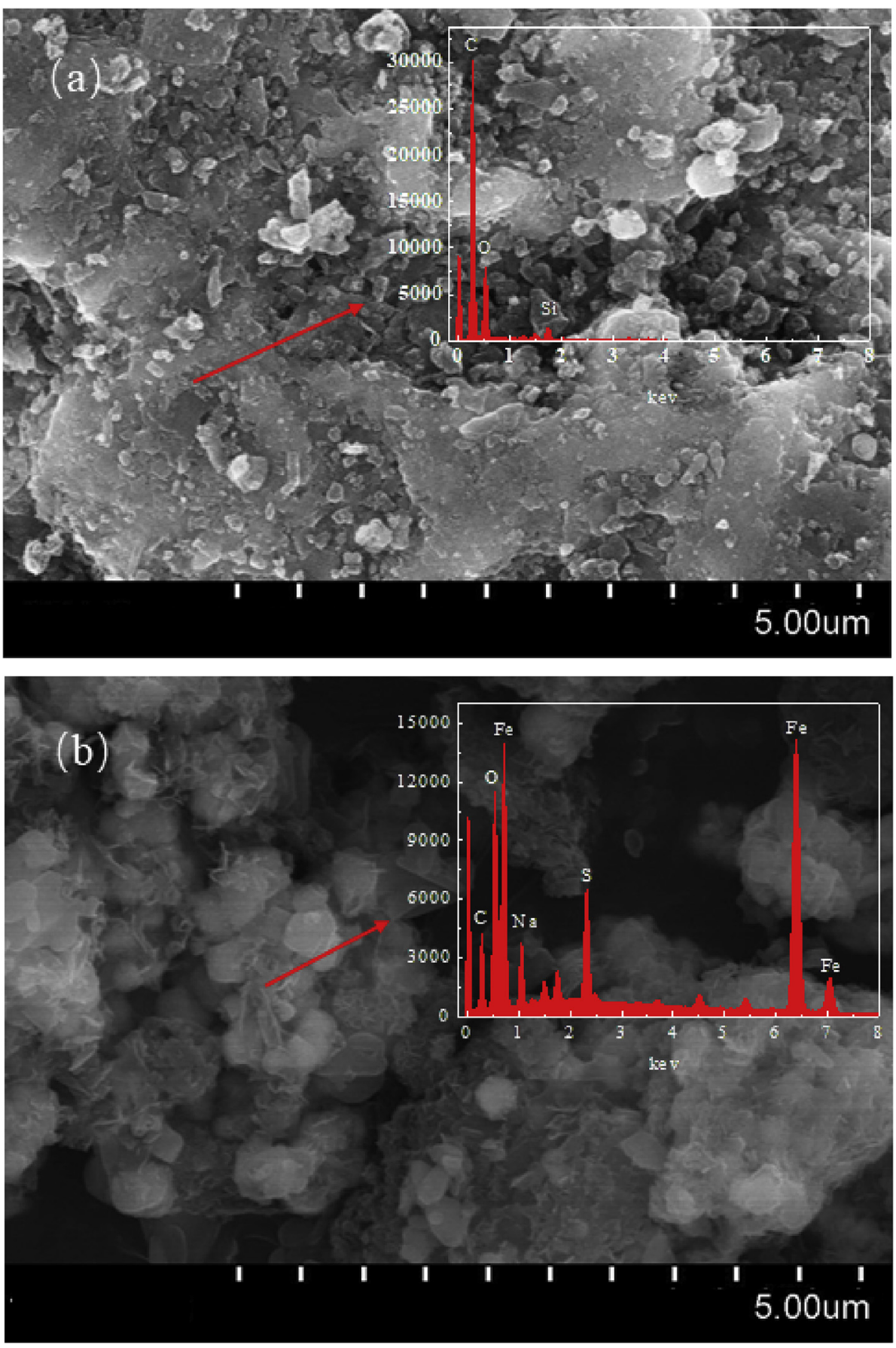

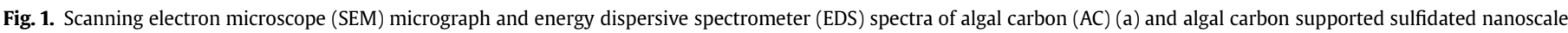
zerovalent iron (S-nZVI/AC) composite (b) synthesized under S/Fe molar ratio of 0.3 in the one-pot synthesis system.

addition and that without S-nZVI. The hysteresis loop of the S-nZVI/ AC composite was very smooth. The coercivity was 154 Oe for the S$\mathrm{nZVI} / \mathrm{AC}$ composite, indicating the ferromagnetic properties of the composite (Niu et al., 2012). Furthermore, the saturation magnetization of the S-nZVI/AC composite was 60 emu $\mathrm{g}^{-1}$ which was similar to that of the $\mathrm{Cu} @ \mathrm{Fe}_{3} \mathrm{O}_{4}$ nanoparticles (Pham et al., 2018). These results showed that the S-nZVI/AC composite could be easily separated by the magnet during the usage. Based on BET analysis, the specific surface area of S-nZVI/AC $\left(56.3 \mathrm{~m}^{2} \mathrm{~g}^{-1}\right)$ was higher than that of AC $\left(25.7 \mathrm{~m}^{2} \mathrm{~g}^{-1}\right)$, which was attributed to the loading of nanoparticles on the AC surface.
The XPS analysis of the composite surface showed the presence of Fe and S elements on the surface of the S-nZVI/AC composite (Fig. 3). According to the Fe (2p) spectra, the peaks corresponding to $\mathrm{Fe}-\mathrm{S}$ (located at $709.6 \mathrm{eV}$ ) and $\mathrm{Fe}^{0}$ (located at $706.9 \mathrm{eV}$ ) were identified. According to the $\mathrm{S}(2 \mathrm{p})$ spectra, peaks of both $\mathrm{S}^{2-}$ (located at $161.2 \pm 0.2 \mathrm{eV}$ ) and polysulfie $\left(\mathrm{S}_{\mathrm{n}}^{2-}\right)$ (located at $163.4 \pm 0.4 \mathrm{eV}$ ) were observed as two doublets, which were similar with the observation of Kim et al. (2011). The XPS analysis on the surface of the composite demonstrated the presence of $\mathrm{FeS}$ and $\mathrm{Fe}^{0}$ on the surface of the S-nZVI/AC composite, confirming the successful loading of the sulfidated nZVI on the algal carbon. 

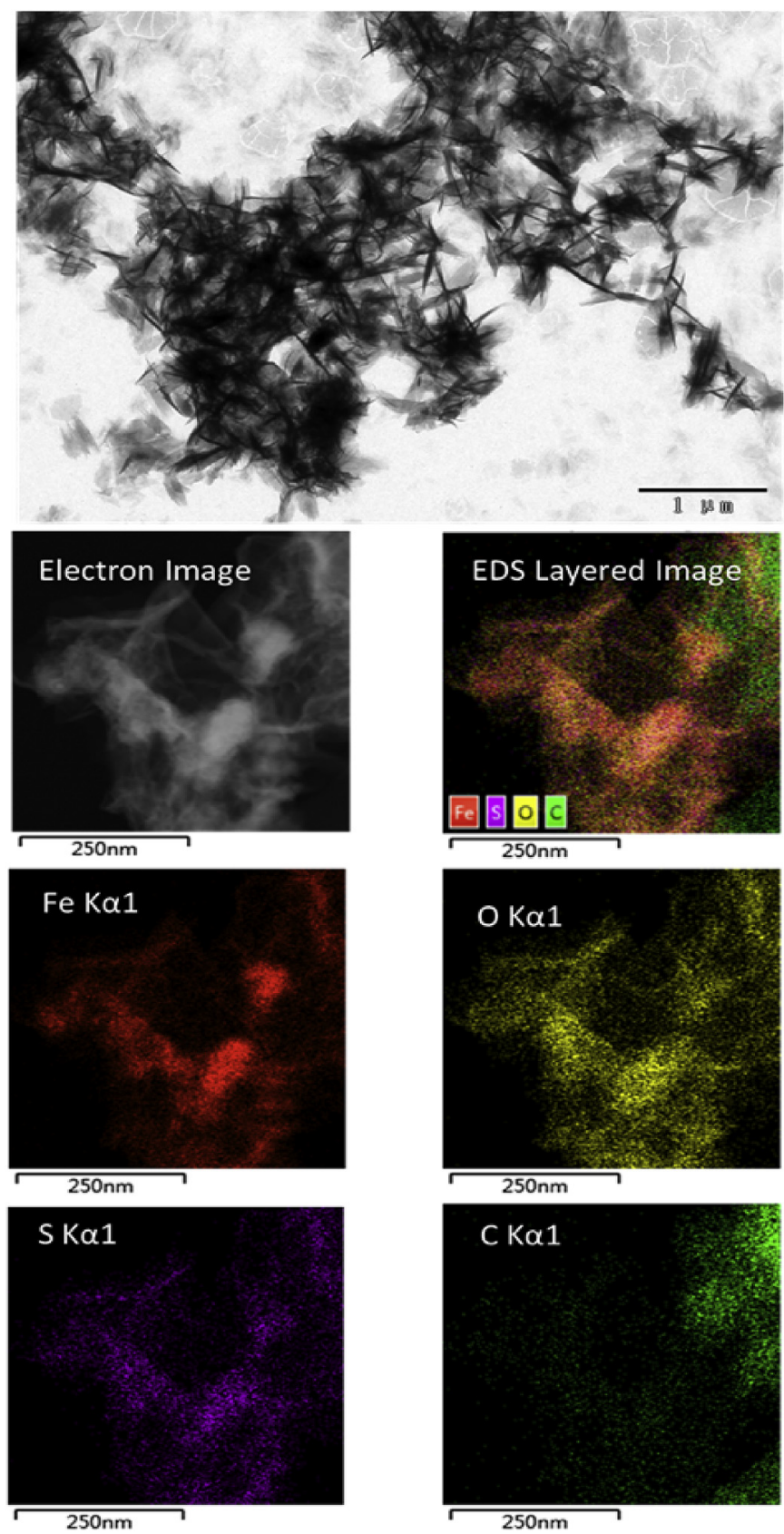

Fig. 2. Transmission electron microscopy (TEM) image and elemental mapping of algal carbon supported sulfidated nanoscale zerovalent iron (S-nZVI/AC) composite synthesized under the $\mathrm{S} / \mathrm{Fe}$ molar ratio of 0.3 in the one-pot synthesis system.

\subsection{Removal of bromate using S-nZVI/AC composite}

The removal of bromate using S-nZVI/AC composite was investigated. Rapid removal of bromate occurred in the presence of SnZVI/AC composite (Fig. 4a). More than 98\% of bromate was removed within $48 \mathrm{~min}$ in the S-nZVI/AC composite (Fe/S ratio of 0.3 ) treatment. To further confirm the effectiveness of S-nZVI/AC composite, tap water was spiked by bromate with $100 \mu \mathrm{g} \mathrm{L}^{-1}$ and approximately $98 \%$ of bromate was also removed within $48 \mathrm{~min}$. To better understand the removal of bromate in DI water using the SnZVI/AC composite, kinetics of bromate removal were investigated. The removal data from the S-nZVI/AC $\left(r^{2}>0.99\right)$ treatments fitted pseudo-first order kinetics well. The highest removal rate constant
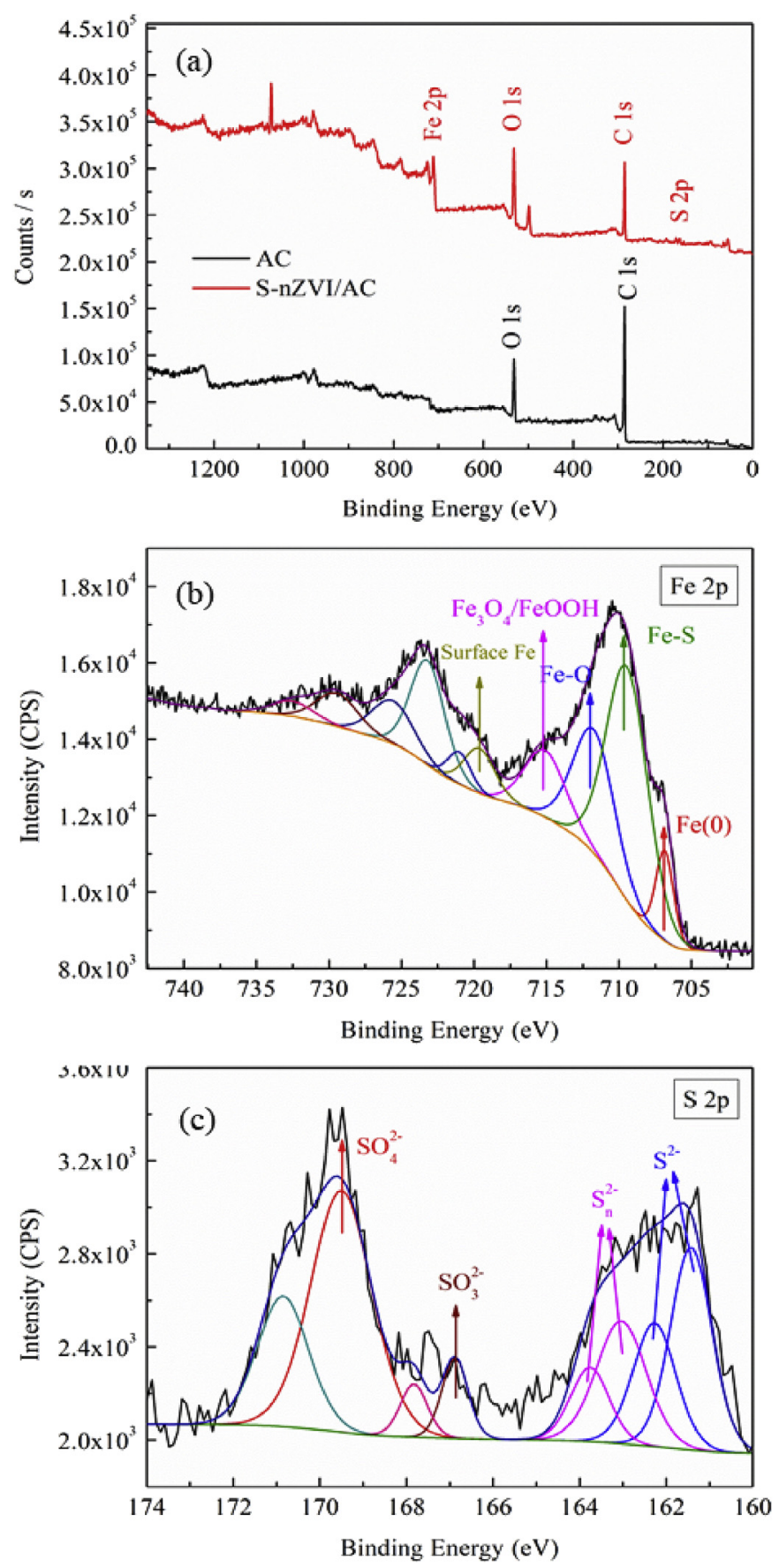

Fig. 3. XPS spectra (a), Fe2p (b), and $S 2 p$ (c) of algal carbon (AC) supported sulfidated nanoscale zerovalent iron ( $\mathrm{S}-\mathrm{nZVI} / \mathrm{AC}$ ) composite synthesized under the S/Fe molar ratio of 0.3 in the one-pot synthesis system.

(k) $\left(0.15 \mathrm{~min}^{-1}\right)$ was observed in the S-nZVI/AC composite treatment while the lowest removal rate constant $(k)\left(0.01 \mathrm{~min}^{-1}\right)$ was observed in the individual algal carbon treatment (control without S-nZVI), indicting that the S-nZVI/AC composite might be a promising water treatment material. To the best of our knowledge, this is the first report on the removal of bromate as the most common bromated disinfection by-product using S-nZVI/AC composite. The presence of the sulfidated nZVI nanoparticles on the algal carbon was essential for the enhancement of the bromate removal. Most of bromate was removed at the end of the experiment in the treatments with the addition of S-nZVI/AC composites while less than 

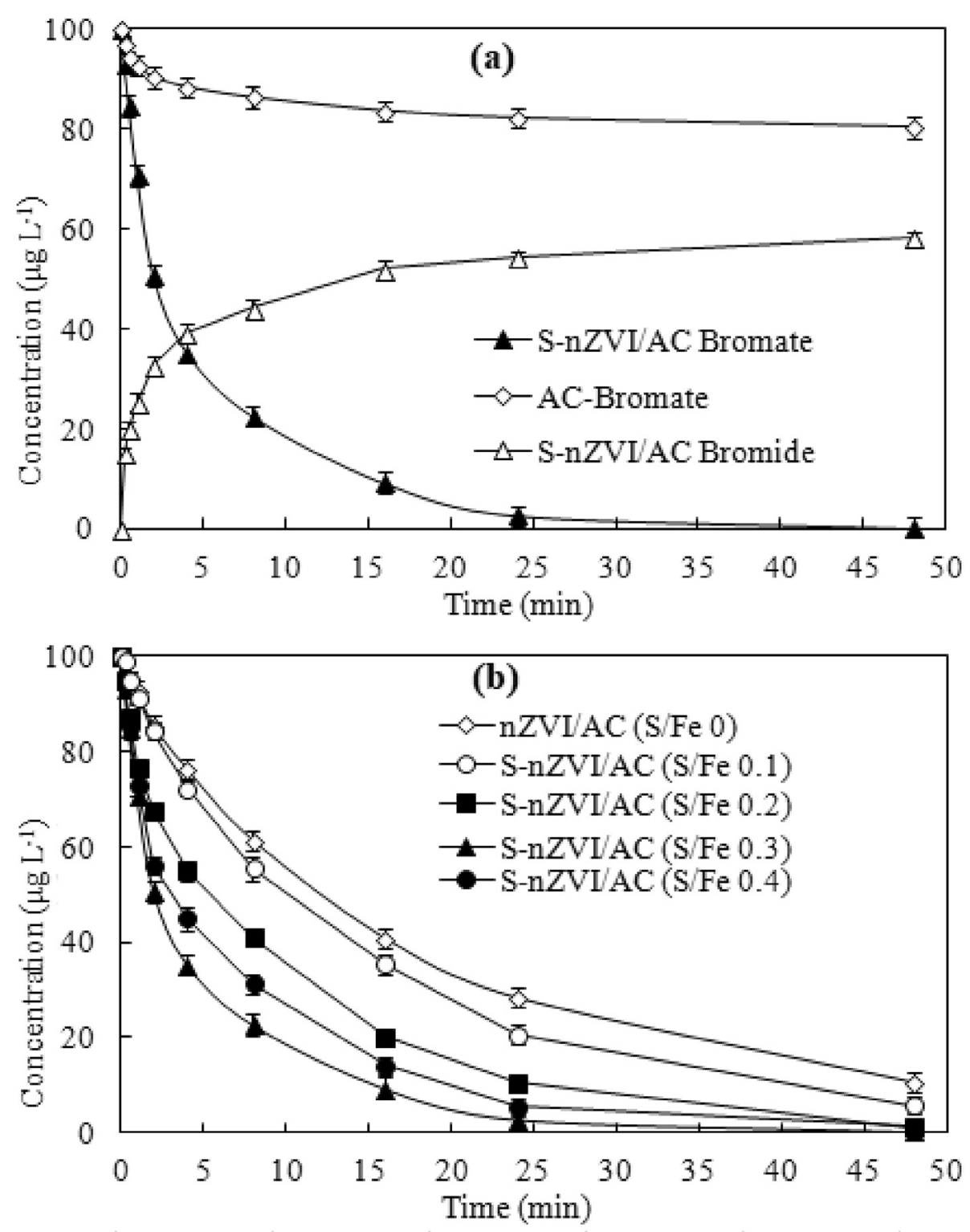

Fig. 4. Effect of algal carbon supported sulfidated nanoscale zerovalent iron (S-nZVI/AC) composite on the removal of bromate.

$10 \%$ of bromate was removed in the algal carbon treatment (control without S-nZVI), indicating that chemical reduction by the S-nZVI nanoparticles supported on the algal carbon rather than adsorption was the main removal process for bromate in the presence of $\mathrm{S}$ $\mathrm{nZVI} / \mathrm{AC}$ composite. Bromate could be transformed into bromide in the presence of ZVI or sulfide (Westerhoff, 2003; Chairez et al., $2010)$. Most of bromate ( $>95 \%$ ) was transformed into bromide in the S-nZVI/AC composite treatment at the end of the experiment, which confirmed that chemical reduction by S-nZVI nanoparticles supported on the algal carbon was the main removal process for bromate in the presence of S-nZVI/AC composite.

In order to evaluate the effect of sulfide-modification on the removal of bromate using S-nZVI/AC composite, the removal of bromate using S-nZVI/AC composite made under different $S / F e$ ratio was evaluated (Fig. 4 b). Removal rate constant $(k)$ of the S$\mathrm{nZVI} / \mathrm{AC}$ composite treatments with $\mathrm{S} / \mathrm{Fe}$ of $0.1,0.2,0.3$, and 0.4 was $0.06,0.10,0.15$, and $0.12 \mathrm{~min}^{-1}$, respectively while that in the $\mathrm{nZVI} /$ $\mathrm{AC}$ composite (S/Fe ratio of 0 ) treatment was just $0.05 \mathrm{~min}^{-1}$. The removal rate constant in the $\mathrm{S}-\mathrm{nZVI} / \mathrm{AC}$ treatment with $\mathrm{S} / \mathrm{Fe}$ ratio of
0.3 was three times higher than that of the nZVI/AC control with S/ Fe ratio of 0 , which confirmed that sulfide-modification is an efficient approach for the improvement of bromate removal using $\mathrm{S}$ nZVI/AC composite. Sulfide-modification has been proved to be an efficient nZVI modification approach for enhancing the removal of other pollutants including trichloroethylene (TCE), diclofenac, and tetrabromobisphenol (Kim et al., 2011; Li et al., 2016; Song et al., 2017). The removal efficiency of the bromate increased sharply when the $\mathrm{S} / \mathrm{Fe}$ ratio increased from 0 to 0.3 while it began to decrease when the $\mathrm{S} / \mathrm{Fe}$ ratio increased further, indicating that high $\mathrm{S} / \mathrm{Fe}$ ratio could also jeopardize the removal efficiency of bromate using S-nZVI/AC composite.

To obtain further information on the mechanism of bromate removal using S-nZVI/AC composite, the synergistic effect between the algal carbon and S-nZVI on the bromate removal using S-nZVI/ AC composite were evaluated (Fig. S2). Compared with the removal efficiency $\left(k=0.07 \mathrm{~min}^{-1}\right)$ of the control experiment without AC (the individual S-nZVI treatment), the removal rate constant $\left(k=0.14 \mathrm{~min}^{-1}\right)$ the related treatments with $\mathrm{AC}(\mathrm{S}-\mathrm{nZVI}+\mathrm{AC}$ 
combined composite treatment) was almost doubled, suggesting the strong synergistic effect between the algal carbon and S-nZVI nanoparticles in the S-nZVI/AC composite. Similar synergistic effects between AC and nZVI (or nFeS) particles were also observed. In the $\mathrm{Fe} / \mathrm{C}$ systems, micro-electrolysis reaction system was formed and the carbon materials could enhance the reduction efficiency through transferring the electrons from galvanic corrosion of iron to the pollutants (Zhang, 2003; Luo et al., 2014). The synergistic effect between the algal carbon and S-nZVI demonstrated the essential role of algal carbon for the enhanced removal of bromate using S-nZVI/AC composite. Additionally, porous carbon materials can also serve as an effective supporter of nZVI for preventing nZVI aggregation and enhancing the removal of pollutants (Quan et al., 2014; Yan et al., 2015; Wang et al., 2017), which indicates that algal carbon could also be the essential supporter for preventing $S$ nZVI aggregation in the S-nZVI/AC composite.

Based on the observations, the removal mechanism of bromate in the presence of S-nZVI/AC composite was proposed (Fig. 5). According to the proposed mechanism, the removal of the bromate was a surface chemical process. On the surface of the composite, the bromate was reduced to bromide by electrons from $\mathrm{Fe}^{0}$ via conductive $\mathrm{FeS}$, carbon, and $\mathrm{Fe}_{\mathrm{x}} \mathrm{O}_{\mathrm{y}}$ while it could also be reduced to bromide directly by FeS, demonstrating that the introduction of carbon and sulfide-modification was an efficient nZVI modification approach for enhancing the removal of pollutants such as bromate. According to the XPS spectra of the composite after the usage (Fig. S3), the presence of $\mathrm{Fe}_{\mathrm{x}} \mathrm{O}_{\mathrm{y}}$ peak and the disappearance of $\mathrm{Fe}^{0}$ and $\mathrm{FeS}$ peak suggested the consumption of $\mathrm{Fe}^{0}$ and $\mathrm{FeS}$. Moreover, the relative atomic concentration of Fe decreased from $7.46 \%$ to $1.44 \%$ after the usage while that of S decreased from $5.26 \%$ to $1.74 \%$, confirming the consumption of Fe and S during the removal of bromate. The consumption of $\mathrm{Fe}^{0}$ and $\mathrm{FeS}$ demonstrated the reliability of the proposed mechanism for bromate removal. Many investigations have demonstrated the enhanced chemical reduction of pollutants in FeS/Fe system or Fe/C systems (Zhang, 2003; Luo et al., 2014; Zou et al., 2019). Since the pollutant could also be reduced by FeS directly at relatively low removal rate (Zou et al., 2019), the direct reduction by FeS could serve as the main removal mechanism when $\mathrm{S} / \mathrm{Fe}$ ratio was relatiely high (e.g. S/Fe ratio of 0.4 ) due to the high content of FeS in the composite, which subsequently led to the decrease in the removal efficiency of bromate.

\subsection{Effect of S-nZVI/AC composite dose, initial concentration of bromate, and reuse on the removal}

The removal efficiency of bromate increased sharply to more than $98 \%$ when the composite dose increased from 0 to $40 \mathrm{mg} \mathrm{L}^{-1}$, and became relatively stable when the composite dose increased from 40 to $60 \mathrm{mg} \mathrm{L}^{-1}$ (Fig. 6a). For this reason, the S-nZVI/AC composite dose for all the experiments except the composite dose experiment was set at $40 \mathrm{mg} \mathrm{L}^{-1}$. The removal of bromate could be enhanced by increasing the composite dose, which was in accordance with other reports where nZVI was used to remove antibiotic metronidazole and 2,4,6-trinitrotoluene (Zhang et al., 2009; Fang et al., 2011).

The relationship between reactant concentration and removal efficiency was studied (Fig. 6b) since the reactant concentration often has great influence on the reaction rate. Increase in the initial concentration caused increase in removal rate constant of bromate. The removal rate constant increased linearly $\left(r^{2}=0.998\right)$ from 0.08 to $0.31 \mathrm{~min}^{-1}$ when the initial concentration increased from 50 to $200 \mu \mathrm{g} \mathrm{L}^{-1}$ while it began to increase slowly to $0.39 \mathrm{~min}^{-1}$ when the initial concentration increased further to $300 \mu \mathrm{g} \mathrm{L}^{-1}$. Relatively high initial concentration might jeopardize the removal of bromate. However, the linear relationship between initial concentration and the maximal removal rate could be maintained even when the initial concentration was relatively high $\left(200 \mu \mathrm{g} \mathrm{L}^{-1}\right)$, suggesting the high bromate removal capacity of the S-nZVI/AC composite. The removal efficiency of the bromate still maintained at high level (>85\%) even after 5 recycles (Fig. $6 \mathrm{c}$ ), confirming the high bromate removal capacity of the S-nZVI/AC composite. Sulfide-modification can effectively inhibit iron oxidation and corrosion of nZVI (Lin et al., 2012), which might subsequently enhance the longevity and reusability of the S-nZVI/AC composite.

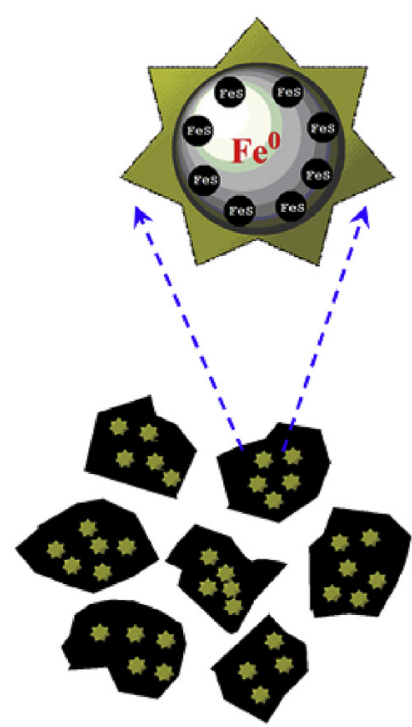

Activated carbon supported flower-like
sulfidated nanoscale zerovalent iron (S-nZVI/AC) composite

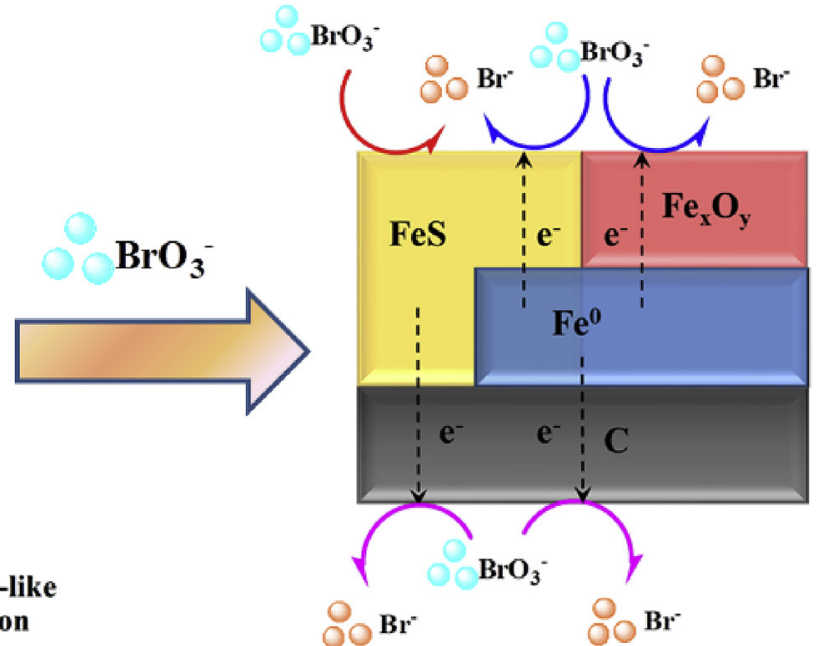

Fig. 5. Proposed mechanism for bromate removal using algal carbon supported sulfidated nanoscale zerovalent iron (S-nZVI/AC) composite. 

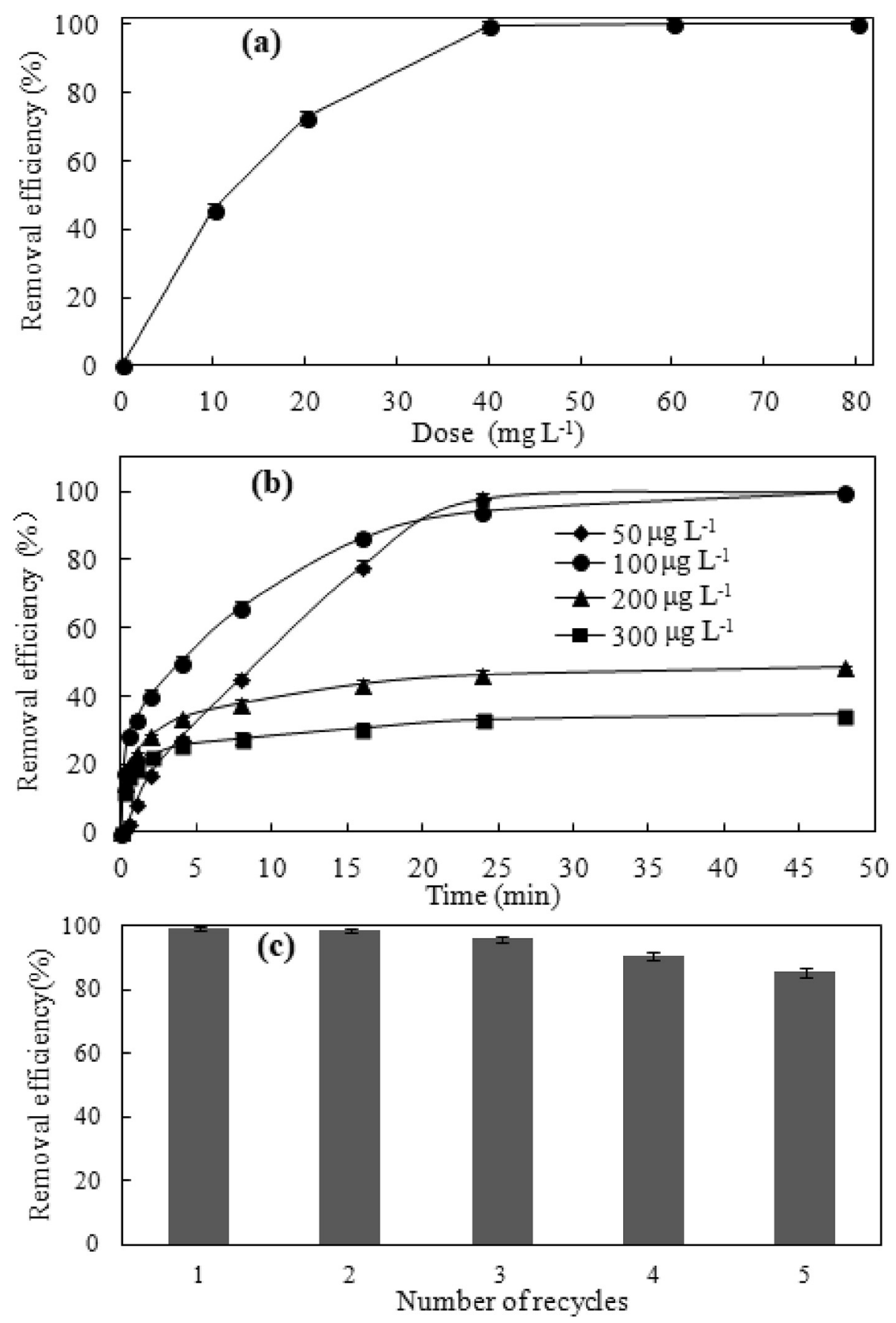

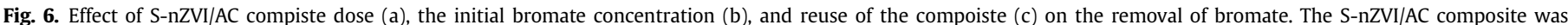
synthesized under the S/Fe molar ratio of 0.3 in the one-pot synthesis system.

\subsection{Effect of environmental factors on the removal of bromate}

Bromate was readily removed under neutral or slight acidic conditions ( $\mathrm{pH}=4-7$ ) (Fig. 7a). The removal efficiency decreased sharply under alkaline conditions. The removal efficiency decreased from $99 \%$ to $85 \%$ when the initial $\mathrm{pH}$ increased from 7.0 to 9.0. Under alkaline conditions, the released ferrous ions were readily collide with hydroxyl ions during iron corrosion, thereby generating ferrous hydroxide precipitation on the surface of nZVI to block reactive sites and hinder the reduction reaction (Zhang, 2003). The removal efficiency also decreased to $88 \%$ under extremely acidic conditions $(\mathrm{pH}=2.0)$. A possible explanation for this decrease was that the ZVI was consumed quickly by the $\mathrm{H}^{+}$but not bromate under extremely acidic conditions, which subsequently led to the decrease in the removal efficiency of bromate. Since the $\mathrm{pH}$ of water usually ranges from 5 to 9 (Wang et al., 2015), the decrease in the removal efficiency under alkaline conditions should not be neglected.

The increase in temperature led to the increase in the removal efficiency (Fig. 7b). The removal rate constant increased from 0.10 to $0.27 \mathrm{~min}^{-1}$ when the temperature increased from $15^{\circ} \mathrm{C}$ to $35^{\circ} \mathrm{C}$. Based on the Arrhenius equation, a simple equation (Lu et al., 2008) which was developed and used to describe the relationship between reaction rate constant and temperature: 

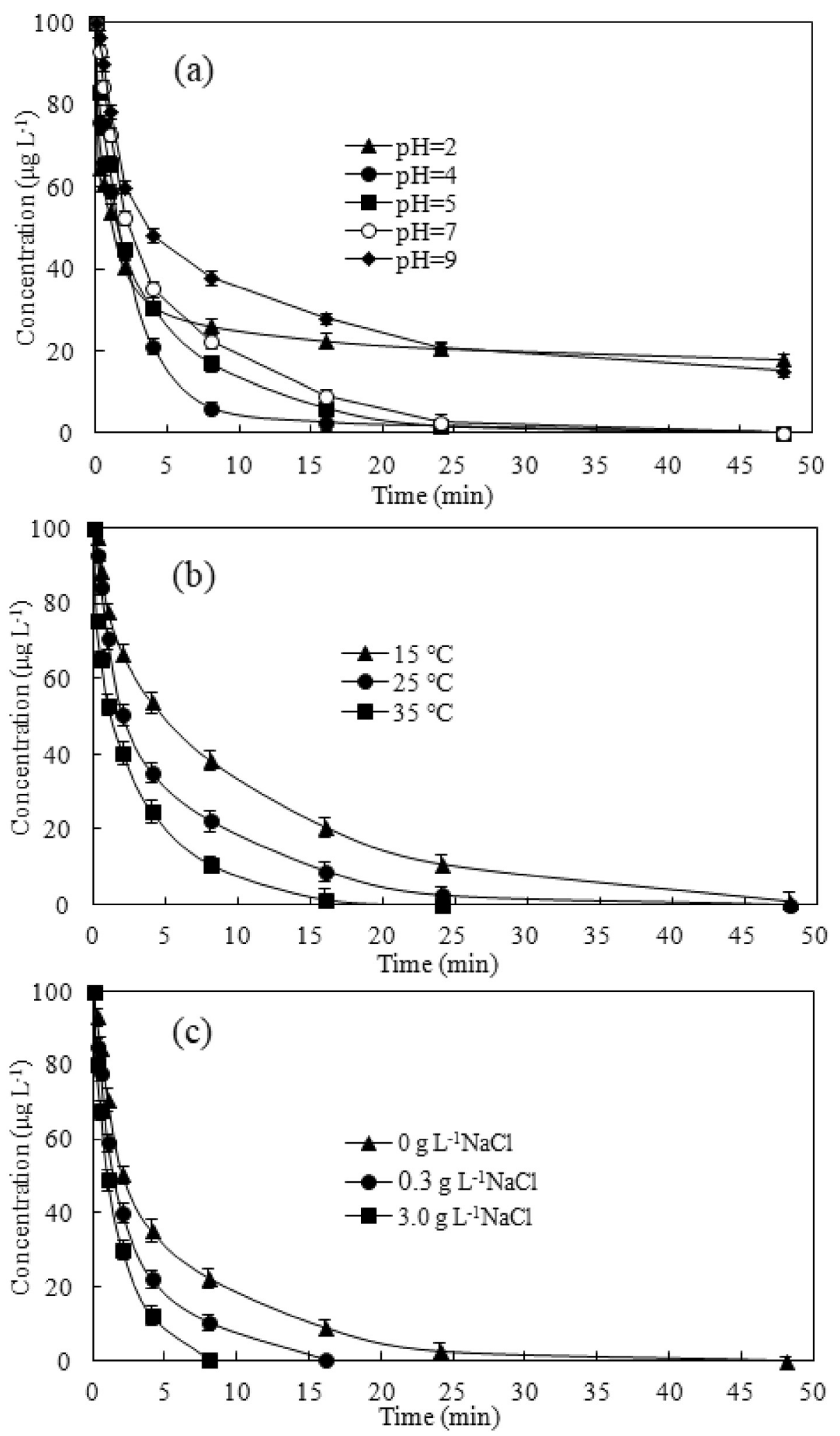

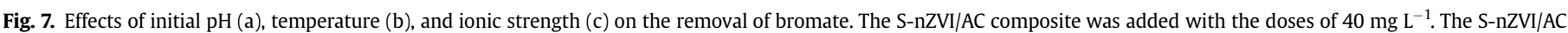
composite was synthesized under the S/Fe molar ratio of 0.3 in the one-pot synthesis system.

$k_{2}=k_{1} e^{\Phi\left(T_{2}-T_{1}\right)}$

where $\Phi$ is the temperature coefficient while $k_{1}$ and $k_{2}$ are the removal rate constants at temperature $T_{1}$ and $T_{2}$, respectively. The temperature coefficient $(\Phi)$ was calculated according to Eq. (1). The result showed that the temperature coefficient $(\Phi)$ for the removal of bromate was $0.05{ }^{\circ} \mathrm{C}^{-1}$ which was much higher than that of 
biodegradation of toxic pollutants such as nonylphenol polyethoxylates $\left(0.01^{\circ} \mathrm{C}^{-1}\right)$ (Lu et al., 2008), indicating that the removal of bromate using S-nZVI/AC composite was greatly influenced by the temperature.

The $\mathrm{NaCl}$ was added into the aqueous solution to investigate the effect of ionic strength on the removal of bromate. The results showed that the increase in ionic strength led to a rapid increase in the removal of bromate (Fig. 7c). The value of $k$ increased from 0.15 to $0.55 \mathrm{~min}^{-1}$ while the $t_{1 / 2}$ decreased from 4.6 to 1.26 min when the ionic strength increased from 0 to $3 \mathrm{~g} \mathrm{~L}^{-1}$. The $\mathrm{nZVI}$ and porous carbon could support micro-electrolysis reaction system for the reduction removal of pollutants (Zhang, 2003). The increase in the ionic strength led to the increase in the electronic conductivity of the S-nZVI/AC micro-electrolysis reaction system, which subsequenlty enhanced the removal efficiency of bromate. The bromate removal rate constant increased almost 4 times when the ionic strength increased from 0 to $3 \mathrm{~g} \mathrm{~L}^{-1}$. Enhanced bromate removal in the presence of $\mathrm{NaCl}$ should not be neglected since the salinity of water usually below $3 \mathrm{~g} \mathrm{~L}^{-1}$ (Wang et al., 2015).

\section{Conclusions}

The magnetic algal carbon supported flower-like sulfidated nZVI composite was firstly synthesized through one-pot method and used for the removal of bromate. Flower-like zerovalent iron nanoparticles were unevenly distributed on the surface of the algal carbon. Efficient removal of bromate using S-nZVI/AC composite was achieved. Most of bromate was removed within $48 \mathrm{~min}$ while less than $10 \%$ of bromate was removed in the algal carbon control without S-nZVI. Triple increase in the removal rate constant was achieved when the $S / F e$ ratio increased from 0 to 0.3. The strong synergistic effects between the $\mathrm{Fe}^{0}$ and $\mathrm{C}$, and $\mathrm{Fe}^{0}$ and $\mathrm{FeS}$ in the $\mathrm{S}$ $\mathrm{nZVI} / \mathrm{AC}$ composite demonstrated that the introduction of carbon and sulfide-modification is an efficient nZVI modification approach for enhancing the removal of pollutants such as bromated disinfection by-product. The bromate was mainly removed through chemical reduction by the S-nZVI nanoparticles supported on the algal carbon. The dose of S-nZVI/AC composite should be optimized before being used for the bromate removal. High initial bromate concentration, temperature, and ionic strength led to the enhancement of bromate removal. The removal efficiency of bromate maintained high level after the recycle of S-nZVI/BC, demonstrating the longevity and reusability of this composite. These findings suggest that S-nZVI/AC composite is a promising material for the purification of water containing bromated disinfection by-product.

\section{CRediT authorship contribution statement}

Jian Lu: Writing - original draft, Conceptualization, Methodology, Software, Writing - review \& editing. Cui Zhang: Investigation, Methodology. Jun Wu: Validation, Methodology, Conceptualization, Writing - review \& editing, Software, Supervision.

\section{Acknowledgements}

This work was supported by National Natural Science Foundation of China (41671319), Taishan Scholars Program of Shandong Province (No. tsqn201812116), One Hundred Talents Program of Chinese Academy of Sciences (Y629041021), Science and Technology Service Network Initiative of the Chinese Academy of Sciences (KFJ-STS-QYZX-114), and Two-Hundred Talents Plan of Yantai (Y739011021).

\section{Appendix A. Supplementary data}

Supplementary data to this article can be found online at https://doi.org/10.1016/j.chemosphere.2020.126257.

\section{References}

Butler, R., Godley, A., Lytton, L., Cartmell, E., 2005. Bromate environmental contamination: review of impact and possible treatment. Crit. Rev. Environ. Sci. Technol. 35, 193-217.

Chairez, M., Luna-Velasco, A., Field, J.A., Ju, X., Sierra-Alvarez, R., 2010. Reduction of bromate by biogenic sulfide produced during microbial sulfur disproportionation. Biodegradation 21, 235-244.

Fang, Z.Q., Chen, J.H., Qiu, X.H., Qiu, X.Q., Cheng, W., Zhu, L.C., 2011. Effective removal of antibiotic metronidazole from water by nanoscale zero-valent iron particles. Desalination 268, 60-67.

Gong, Y., Gai, L., Tang, J., Fu, J., Wang, Q., Zeng, E.Y., 2017. Reduction of Cr(VI) in simulated groundwater by FeS-coated iron magnetic nanoparticles. Sci. Total Environ. 595, 743-751.

Gong, Y., Liu, Y., Xiong, Z., Kaback, D., Zhao, D., 2012. Immobilization of mercury in field soil and sediment using carboxymethyl cellulose stabilized iron sulfide nanoparticles. Nanotechnology 23, 294007.

Gong, Y., Tang, J., Zhao, D., 2016. Application of iron sulfide particles for groundwater and soil remediation: a review. Water Res. 89, 309-320.

Han, Y.S., Gallegos, T.J., Demond, A.H., Hayes, K.F., 2011. FeS-coated sand for removal of arsenic(III) under anaerobic conditions in permeable reactive barriers. Water Res. 45, 593-604.

Hong, S.Q., Deng, S.B., Yao, X.L., Wang, B., Wang, Y.J., Huang, J., Yu, G., 2016. Bromate removal from water by polypyrrole tailored activated carbon. J. Colloid Interface Sci. 467, 10-16.

Kim, E.J., Kim, J.H., Azad, A.M., Chang, Y.S., 2011. Facile synthesis and characterization of Fe/FeS nanoparticles for environmental applications. ACS Appl. Mater. Interfaces 3, 1457-1462.

Kurokawa, Y., Maekawa, A., Takahashi, M., Hayashi, Y., 1990. Toxicity and carcinogenicity of potassium bromate: a new renal carcinogen. Environ. Health Perspect. 87, 309-335.

Li, D., Mao, Z., Zhong, Y., Huang, W., Wu, Y., Peng, P.A., 2016. Reductive transformation of tetrabromobisphenol A by sulfidated nano zerovalent iron. Water Res. 103, 1-9.

Lin, K., Ding, J., Huang, X., 2012. Debromination of tetrabromobisphenol A by nanoscale zerovalent iron: kinetics, influencing factors, and pathways. Ind. Eng. Chem. Res. 51, 8378-8385.

Lin, K.-Y.A., Lin, J.-Y., Lien, H.-L., 2017. Valorization of aluminum scrap via an acidwashing treatment for reductive removal of toxic bromate from water. Chemosphere 172, 325-332.

Lyu, H., Tang, J., Huang, Y., Gai, L., Zeng, E.Y., Liber, K., Gong, Y., 2017. Removal of hexavalent chromium from aqueous solutions by a novel biochar supported nanoscale iron sulfide composite. Chem. Eng. J. 322, 516-524.

Lu, J., Jin, Q., He, Y., Wu, J., Zhang, W., Zhao, J., 2008. Anaerobic degradation behavior of nonylphenol polyethoxylates in sludge. Chemosphere 71, 345-351.

Lu, J., Zhang, C., Wu, J., Luo, Y., 2017. Adsorptive removal of bisphenol A using Ndoped biochar made of Ulva prolifera. Water, Air, Soil Pollut. 228, 327.

Luo, J., Song, G., Liu, J., Qian, G., Xu, Z.P., 2014. Mechanism of enhanced nitrate reduction via micro-electrolysis at the powdered zero-valent iron/activated carbon interface. J. Colloid Interface Sci. 435, 21-25.

Marco, Y., García-Bordejé, E., Franch, C., Palomares, A.E., Yuranova, T., KiwiMinsker, L., 2013. Bromate catalytic reduction in continuous mode using metal catalysts supported on monoliths coated with carbon nanofibers. Chem. Eng. J 230, 605-611.

Niu, H.Y., Wang, Y.X., Zhang, X.L., Meng, Z.F., Cai, Y.Q., 2012. Easy synthesis of surface-tunable carbon-encapsulated magnetic nanoparticles: adsorbents for selective isolation and preconcentration of organic pollutants. ACS Appl. Mater. Interfaces 4, 286-295.

Pham, V.L., Kim, D.G., Ko, S.O., 2018. Oxidative degradation of the antibiotic oxytetracycline by Cu@Fe304 core-shell nanoparticles. Sci. Total Environ. 631-632, 608-618.

Qian, L., Zhang, W., Yan, J., Han, L., Chen, Y., Ouyang, D., Chen, M., 2017. Nanoscale zero-valent iron supported by biochars produced at different temperatures: synthesis mechanism and effect on $\mathrm{Cr}(\mathrm{VI})$ removal. Environ. Pollut. 223, $153-160$.

Quan, G., Sun, W., Yan, J., Lan, Y., 2014. Nanoscale zero-valent iron supported on biochar: characterization and reactivity for degradation of acid orange 7 from aqueous solution. Water, Air, Soil Pollut. 225, 2195.

Shcherban, N.D., Yaremov, P.S., Ilyin, V.G., Ovcharova, M.V., 2014. Influence of the method of activation on the structural and sorption properties of the products of carbonization of sucrose. J. Anal. Appl. Pyrol. 107, 155-164.

Song, S., Su, Y., Adeleye, A.S., Zhang, Y., Zhou, X., 2017. Optimal design and characterization of sulfide-modified nanoscale zerovalent iron for diclofenac removal. Appl. Catal. B Environ. 201, 211-220.

Su, Y., Adeleye, A.S., Keller, A.A., Huang, Y., Dai, C., Zhou, X., Zhang, Y., 2015. Magnetic sulfide-modified nanoscale zerovalent iron (S-nZVI) for dissolved metal ion removal. Water Res. 74, 47-57.

Sun, C., Ning, D., Hao, A., Hao, C., Zhai, J., 2015. Electrocatalytic reduction of bromate 
based on Pd nanoparticles uniformly anchored on polyaniline/SBA-15. Chemosphere 141, 243-249.

Sun, P., Li, Y., Meng, T., Zhang, R., Song, M., Ren, J., 2018. Removal of sulfonamide antibiotics and human metabolite by biochar and biochar $/ \mathrm{H}_{2} \mathrm{O}_{2}$ in synthetic urine. Water Res. 147, 91-100.

Wang, S., Gao, B., Li, Y., Creamer, A.E., Feng, H., 2017. Adsorptive removal of arsenate from aqueous solutions by biochar supported zero-valent iron nanocomposite: batch and continuous flow tests. J. Hazard Mater. 322, 172-181.

Wang, Y., Lu, J., Wu, J., Liu, Q., Zhang, H., Jin, S., 2015. Adsorptive removal of fluoroquinolone antibiotics using bamboo biochar. Sustainability 7, 12947-12957.

Wang, Y., Shao, Q., Huang, S.S., Zhang, B., Xu, C., 2018. High performance and simultaneous sequestration of $\mathrm{Cr}(\mathrm{VI})$ and $\mathrm{Sb}(\mathrm{III})$ by sulfidated zerovalent iron. J. Clean. Prod. 191, 436-444.

Wei, J., Liu, Y., Li, J., Zhu, Y., Yu, H., Peng, Y., 2019. Adsorption and co-adsorption of tetracycline and doxycycline by one-step synthesized iron loaded sludge biochar. Chemosphere 236, 124254.

Westerhoff, P., 2003. Reduction of nitrate, bromate, and chlorate by zero valent iron $\left(\mathrm{Fe}^{0}\right)$. J. Environ. Eng. 129, 10-16.

Wu, W., Li, J., Niazi, N.K., Müller, K., Chu, Y., Zhang, L., Yuan, G., Lu, K., Song, Z Wang, H., 2016. Influence of pyrolysis temperature on lead immobilization by chemically modified coconut fiber-derived biochars in aqueous environments.
Environ. Sci. Pollut. Res. 23, 22890-22896

Yan, J. Lu, H. Gao, W. Song, X., Chen, M., 2015. Biochar supported nanoscale zerovalent iron composite used as persulfate activator for removing trichloroethylene. Bioresour. Technol. 175, 269-274.

Yao, H., Lu, J., Wu, J., Lu, Z., Wilson, P.C., Shen, Y., 2012. Adsorption of fluoroquinolone antibiotics by wastewater sludge biochar: role of the sludge source. Water, Air, Soil Pollut. 224, 1370

Zhang, C., Lu, J., Wu, J., Luo, Y., 2019. Phycoremediation of coastal waters contaminated with bisphenol A by green tidal algae ulva prolifera. Sci. Total Environ. 661, 55-62.

Zhang, H., Deng, R., Wang, H., Kong, Z., Dai, D., Jing, Z., Jiang, W., Hou, Y., 2016. Reduction of bromate from water by zero-valent iron immobilized on functional polypropylene fiber. Chem. Eng. J. 292, 190-198.

Zhang, W.X., 2003. Nanoscale iron particles for environmental remediation: an overview. J. Nano Res. 5, 323-332.

Zhang, X., Lin, Y.M. Chen, Z.L., 2009. 2,4,6-Trinitrotoluene reduction kinetics in aqueous solution using nanoscale zero-valent iron. J. Hazard Mater. 165, 923-927.

Zou, H., Hu, E., Yang, S., Gong, L., He, F., 2019. Chromium(VI) removal by mechanochemically sulfidated zero valent iron and its effect on dechlorination of trichloroethene as a co-contaminant. Sci. Total Environ. 650, 419-426. 